\title{
Effect of Veronal Anaesthesia upon the Epinephrine Secretion and the Blood Sugar Concentration.
}

\author{
By \\ Hiroshi Sato and Tune. Degti. \\ （佐 藤 熙） (出口恒三郎) \\ (From the Physiological Laboratory of Prof. Y. Satake, \\ Tohoku Imperial University, Sendai.)
}

The velocity with which the epinephrine is liberated from the suprarenal gland of dogs, non-anaesthetized is not subject to change towards a particular direction by applying various kinds of anaesthetics, such as ether, urethane, morphine, chloralose and avertin.')

In this experiment veronal was tested in the same manner.

In the dogs, in which particular regions were previously deafferented, that is $\mathrm{D}_{10}-\mathrm{L}_{3}$ dorsal roots severed, the lumbar route operation was carried out for collecting suprarenal vein blood samples without anaesthetizing, evoking any pain and opening the abdominal cavity. The epinephrine concentration was estimated by means of the rabbit intestine segment method and the blood sugar by the $\mathrm{H}$ a gedorn and Jensen method.

„Veronal-Natrium" of E. Merck, was dissolved freshly before use in $0.9 \% \mathrm{NaCl}$-solution so as to contain $15-17 \%$, and intravenously injected in doses of $0.16,0.25,0.3$ and $0.47 \mathrm{grm}$. per kilo of body weight.

The poisoning symptoms corresponded to the amount given, that is in Exp. 1 (0.16 grm. per kilo) and Exp. 4 (0.25 grm. per kilo) poisoning was not so profound; in Exp. 1 the reflexes never disappeared, the animal never slept profoundly. The nictating membrane protruded largely about one hour after veronal, but two hours later it was apt to recover almost completely, and in Exp. 4 the reflexes and the muscle tone also did not wholly disappear, but the sleep was deeper com-

1) Kod a ma, J. of Biophysics, 1924, 1, 79; S a to and A o mu ra, Tohoku J. of Exp. Med., 1930, 15, 17; Sato and $0 \mathrm{hmi}$, Ibid., 1933, 21, 411, 433; S ato, S a tow and Degti, Ibid., 1934, 24, 485. 
TABLE.

The epinephrine output, blood sugar content, etc. after intravenous injection of veronal in de-afferented dogs.

\begin{tabular}{|c|c|c|c|c|c|c|c|c|c|c|c|c|c|}
\hline \multirow{3}{*}{ 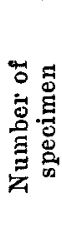 } & \multirow{3}{*}{ 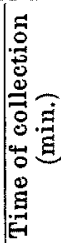 } & \multicolumn{4}{|c|}{ Blood flow (c.c.) } & \multicolumn{3}{|c|}{ Epinephrine (mgrm.) } & \multirow{3}{*}{ 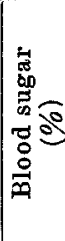 } & \multirow{3}{*}{ 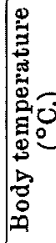 } & \multirow{3}{*}{ 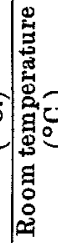 } & \multirow{3}{*}{ 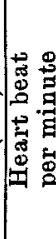 } & \multirow{3}{*}{ 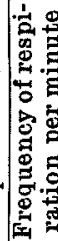 } \\
\hline & & \multirow[b]{2}{*}{ 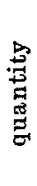 } & \multirow[b]{2}{*}{ 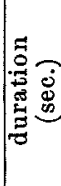 } & \multirow{2}{*}{ 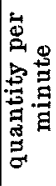 } & \multirow{2}{*}{ 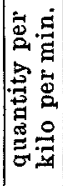 } & \multirow[b]{2}{*}{$\begin{array}{c}\text { content } \\
\text { in } \\
1 \text { c.c. } \\
\text { blood }\end{array}$} & \multicolumn{2}{|c|}{ output } & & & & & \\
\hline & & & & & & & $\begin{array}{c}\text { per } \\
\text { minute }\end{array}$ & $\begin{array}{c}\text { per } \\
\text { kilo } \\
\text { per } \\
\text { minute }\end{array}$ & & & & & \\
\hline
\end{tabular}

Dog 1. 15.2 kilos ค. 11. IX. 1933.

(2. V. 1933. 11.7 kilos, $\mathrm{D}_{10}-\mathrm{L}_{3}$ dorsal spinal roots severed.) 10:00-11:00 a.m. Left lumbar route preparation.

1:20 p.m. Experimented on as follows.

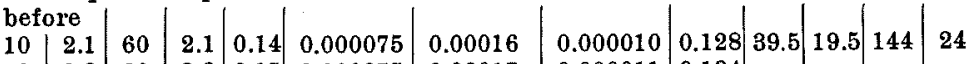

\begin{tabular}{r|r|r|r|r|r|r|r|r|r|} 
II & $\mathbf{9}$ & 2.3 & 60 & 2.3 & 0.15 & 0.000075 & 0.00017 & 0.000011 & 0.134 \\
\hline
\end{tabular}

$1: 30$ p.m. 16 c.c. veronal solution ( $3 \mathrm{grms}$. veronal in $20 \mathrm{c.c}$. of $0.9 \% \mathrm{NaCl}-$ solution) injected into v. saphena dextra. (About $0.16 \mathrm{grm}$. perkilo) Soon later the animal quiet.

\begin{tabular}{|c|c|c|c|c|c|c|c|c|c|c|c|c|c|}
\hline & afte & & & & & & & & & & & & \\
\hline III & 15 & 1.9 & 60 & 1.9 & 0.13 & 0.000075 & 0.00014 & 0.000009 & 0.121 & 39.0 & 19.5 & 180 & 24 \\
\hline IV & 16 & 2.1 & 60 & 2.1 & 0.14 & & & & & & & & \\
\hline $\mathbf{v}$ & 50 & 1.7 & 60 & 1.7 & 0.11 & 0.0001 & 0.00017 & 0.000011 & 0.135 & & & & \\
\hline VI & 51 & 1.8 & 60 & 1.8 & 0.12 & & & & & 37.7 & 20 & 180 & 25 \\
\hline VII & 90 & 1.1 & 60 & 1.1 & 0.07 & 0.0001 & 0.00011 & 0.000007 & 0.126 & & & & \\
\hline VIII & 91 & 1.1 & 60 & 1.1 & 0.07 & & & & & 39.5 & 20 & 235 & \\
\hline IX & 130 & 1.0 & 60 & 1.0 & 0.07 & 0.0001 & 0.00010 & 0.000007 & 0.126 & & & & \\
\hline $\mathbf{X}$ & 131 & 0.8 & 60 & 0.8 & 0.05 & & & & & 39.7 & 20 & 235 & \\
\hline $\mathrm{XI}$ & 160 & 1.2 & 60 & 1.2 & 0.08 & 0.0001 & 0.00012 & 0.000008 & 0.114 & & & & \\
\hline XII & 161 & 1.3 & 60 & 1.3 & 0.09 & & & & & 39.3 & 19 & 228 & \\
\hline XIII & 190 & 1.4 & 60 & 1.4 & 0.09 & 0.0001 & 0.00014 & 0.000009 & 0.123 & 39.6 & 19 & 234 & \\
\hline
\end{tabular}
4:50 p.m. Shed about 80 c.c. blood from lumbodorsal artery.

5:00 Cut off the left splanchnic nerv. The wound sewed up.

Anaesthesia shallow.

1:45 Reflexes +; nictating membrane was stretched.

2:25 Muscle tone + ; shivering; reflexes + .

3:0 and 4:10 Almost as above.

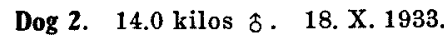

(11. V. 1933. 12.8 kilos. $\mathrm{D}_{10}-\mathrm{L}_{3}$ dorsal spinal roots severed.)

(Both limbs quite normal.)

10:00-11:00 a.m. Left lumbar route preparation.

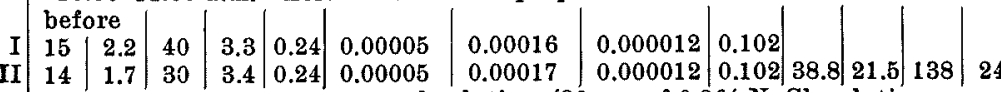

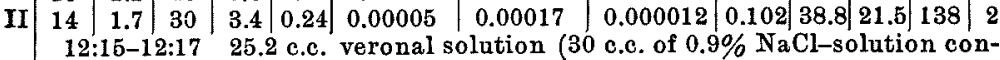
taining 5 grms. veronal) injected into the right v. saphena (0.3 grm. per kilo).

5 minutes later the animal quiet. Reflexes + . Nictating membran was stretched. Muscle tone + .

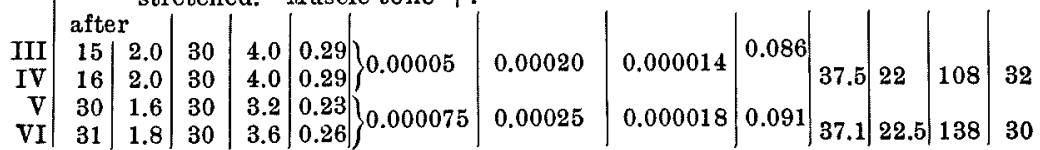




\begin{tabular}{|c|c|c|c|c|c|c|c|c|c|c|c|c|c|}
\hline \multirow{3}{*}{ 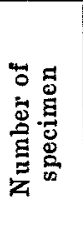 } & \multirow{3}{*}{ 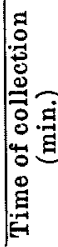 } & \multicolumn{4}{|c|}{ Blood flow (c.c.) } & \multicolumn{3}{|c|}{ Epinephrine (mgrm.) } & \multirow{3}{*}{ 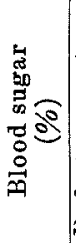 } & \multirow{3}{*}{ 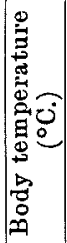 } & \multirow{3}{*}{ 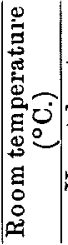 } & \multirow{3}{*}{ 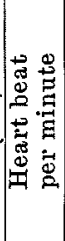 } & \multirow{3}{*}{ 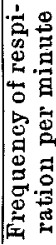 } \\
\hline & & \multirow[b]{2}{*}{$\begin{array}{l}\text { 密 } \\
\text { 吾 } \\
\text { 㤩 }\end{array}$} & \multirow[b]{2}{*}{ 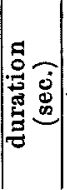 } & \multirow{2}{*}{ 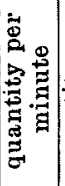 } & \multirow{2}{*}{ 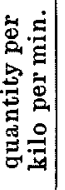 } & \multirow[b]{2}{*}{$\begin{array}{c}\text { content } \\
\text { in } \\
1 \text { c.c. } \\
\text { blood }\end{array}$} & \multicolumn{2}{|c|}{ output } & & & & & \\
\hline & & & & & & & $\begin{array}{c}\text { per } \\
\text { minute }\end{array}$ & $\begin{array}{c}\text { per } \\
\text { kilo } \\
\text { per } \\
\text { minute }\end{array}$ & & & & & \\
\hline & aft & & & & & & & & & & & & \\
\hline VII & 60 & 1.4 & 30 & 2.8 & 0.20 & & & & & & & & \\
\hline VIII & 61 & 1.4 & 30 & 2.8 & 0.20 & & 0.00021 & 0.000015 & 0.093 & 36.1 & $\mid 22.5$ & \begin{tabular}{|l|l}
5 & 138
\end{tabular} & 30 \\
\hline IX & 90 & 1.2 & 30 & 2.4 & 0.17 & & & & & & & & \\
\hline $\bar{x}$ & 91 & 1.3 & 30 & 2.6 & 0.19 & 0.000075 & 0.00019 & 0.000014 & 0.100 & 35.9 & 23 & 138 & 20 \\
\hline $\mathbf{X I}$ & 120 & 1.2 & 30 & 2.4 & 0.17 & 0000075 & & & & & & & \\
\hline XII & 121 & 1.0 & 30 & 2.0 & 0.14 & 0.000075 & 0.00016 & 0.000012 & 0.091 & 35.6 & 3) 22.5 & \begin{tabular}{|l|l}
5 & 144
\end{tabular} & 21 \\
\hline XIII & 180 & 0.7 & 30 & 1.4 & 0.10 & & & & & & & & \\
\hline XIV & 181 & 0.6 & 30 & 1.2 & 0.09 & 0.00010 & 0.00012 & 0.000009 & 0.102 & & & & \\
\hline $\mathbf{X V}$ & 181 & 0.5 & 30 & 1.0 & 0.07 & & & & & 35.4 & 22.5 & \begin{tabular}{l|l}
5 & 156
\end{tabular} & 27 \\
\hline XVI & 240 & 2.1 & 60 & 2.1 & 0.15 & 000010 & 0.00020 & 0000015 & & & & & \\
\hline XVII & 241 & 1.0 & 30 & 2.0 & 0.14 & $>0.00010$ & 0.00020 & 0.000015 & 0.100 & 35.9 & 21.5 & \begin{tabular}{|l|l}
5 & 132
\end{tabular} & 30 \\
\hline & & & & & & c.c. & & & al : & tery. & & & \\
\hline & & & & & & & & & & & & & \\
\hline & & 30 & $\begin{array}{l}\text { Quie } \\
\text { mbra }\end{array}$ & $t, r e f$ & lexes & +, anaesth & esia som & what deep & pupils & Is sma & Ill, nic & ictati & \\
\hline & & 15 & Slept & & $: 40 \mathrm{M}$ & uscle tone & 土. $2: 15$ & Muscle & 1e - & , refle & xes \pm & \pm & \\
\hline & & & OH: & & & 15 Muscle & 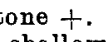 & 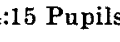 & mall & $1 ; \mathrm{x}$ & exes & $3+$ & \\
\hline
\end{tabular}

Dog 3. 11.0 kilos ㅇ. 15. XI. 1933.

(26. IV. 1933. 13.0 kilos. $\mathrm{D}_{9}-\mathrm{L}_{3}$ dorsal spinal roots severed.)

(VIII. '33 6 youngs were born.)

9:45-10:40 Left lumbar route preparation; both hind legs quite normal.

12:20 Experimented on as follows :-

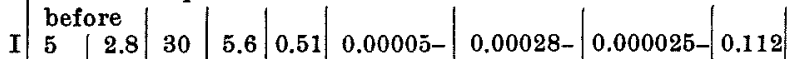

II $4 \frac{1}{2} \mid$\begin{tabular}{l|l|l|l|l|l|l|l|l|l|l|l|l}
3.0 & 30 & 6.0 & 0.55 & 0.00005 & 0.00030 & 0.000026 & & 39.1 & 18 & 108 & 20
\end{tabular} 12:25-12:30 c.c. veronal solution ( 35 c.c. of $0.9 \% \mathrm{NaCl}$-solution containing 6 grms. veronal) introduced into v. saphena dextra. (About $0.47 \mathrm{grm}$. per kilo). Nictitating membrane was stretched. after

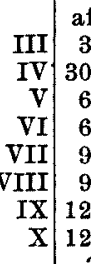

\begin{tabular}{l|l|l|l|}
.7 & 30 & 3.4 & 0.31 \\
\hline & 30 & 3.6 & 0.33 \\
\hline
\end{tabular}

\begin{tabular}{l|l|l|l|l}
.8 & 30 & 3.6 & 0.33 & 0.00005
\end{tabular}

\begin{tabular}{|l|l|l|l|l}
1.8 & 40 & 2.7 & 0.25 & 0.00005 \\
\hline
\end{tabular}

3.30 .30

$2.2+40$

\begin{tabular}{ll|l|l|l|l}
1.8 & 30 & 3.6 & 0.33 & 0.00005 \\
\hline
\end{tabular}

\begin{tabular}{|l|l|l|l|l|l|}
2.4 & 30 & 4.8 & 0.44 & 0.00005
\end{tabular}

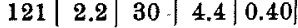

3:00 Died. Indifferent blood collected from v, cava. inf.

\begin{tabular}{|r|r|r|r|r|r}
0.000016 & 0.108 & & & & \\
0.000012 & 0.112 & 36.9 & 19.5 & 135 & 10 \\
& 0.119 & 36.0 & 19 & 105 & 8 \\
0.000016 & & 35.3 & 18 & 90 & 8 \\
0.000022 & 0.114 & & & & \\
& & 34.2 & 18.5 & 96 & 8
\end{tabular}

Before the veronal injection, heart rate irregular.

5 minutes after the injection, laid down weakly. 1:00 Heart rate regular, pupil small, corneal reflex \pm , muscle tone -. 1:30 Lay quietly, the other conditions same. Colour of specimen V.-X. dark.

2:30 Respiration irregular.

Intestine tracings reproduced for example.

Dog 4. 16.8 kilos 우 13. XII. 1933.

(2. V. 1933. 11.7 kilos. $\mathrm{D}_{10}-\mathrm{L}_{3}$ dorsal spinal roots severed.

11. IX. " 15.2 " Left lumbar route preparation for veronal experiment: Dog 1. L splanchnicotomy.)

10:00-11:30 a.m. Right lumbar route preparation. 


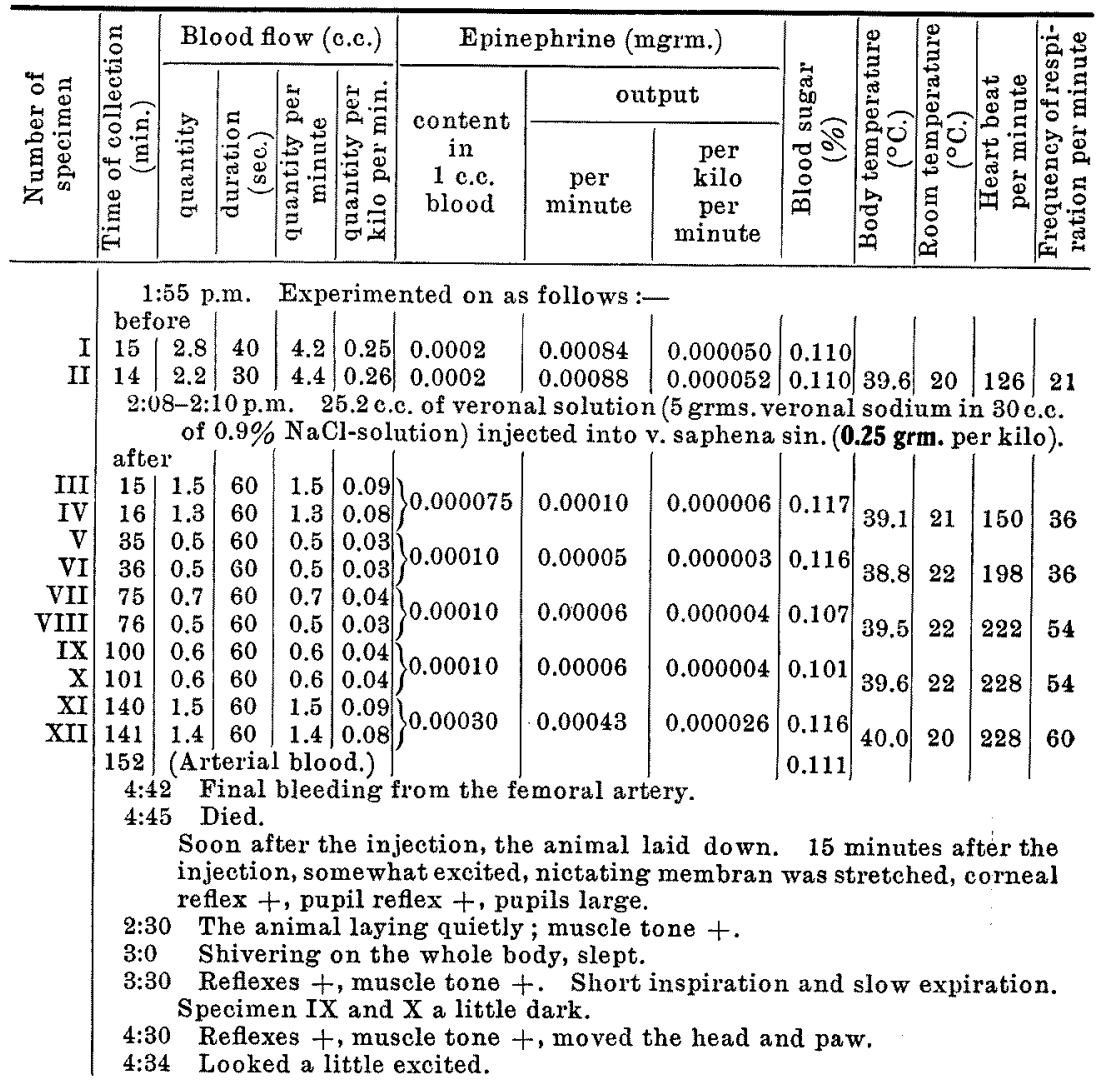

pared with Exp.1. A short time after injecting veronal solution the animal was slightly excited, 2 hours after veronal the animal appeared somewhat excited, that is the recovery already had set in at this time.

When $0.3 \mathrm{grm}$. veronal per kilo was dosed, the poisoning was more severe; the reflexes became very stupid, the muscle tone disappeared and sleep was profound. 4 hours after the injection some recovery was noted. $0.47 \mathrm{grm}$. veronal per kilo produced a too severe poisoning which resulted in the death of the animal.

The blood flow from the cannula inserted into the lumbo-suprarenal vein diminished gradually on receiving veronal in the doses above given. The initial values were 0.15 c.c. per kilo per minute, 0.24 c.c., 0.55 c.c. and 0.26 c.c. After veronal it was reduced to 0.05 c.c. per kilo per minute ( 2 hours), 0.07 c.c. ( 3 hours), 0.22 c.c. ( 1 hour) and 0.03 c.c. (half an hour). The figures in parentheses refer to the 


\section{Intestine tracings for Dog 3. (Reduced to $\frac{3}{5}$ )}

In all the intestine tracings, at the mark " $x$ " atropine-Tyrode's solution, in which the rabbit intestine segment was beating rhythmically, was replaced by indifferent blood solution, and at the "numeral" the indifferent blood solution to which a certain quantity of adrenalin chloride of $\mathrm{S}$ a $\mathrm{nky}$ o Co. was added, or by the blood specimen solution. All the blood solutions were prepared by diluting with 4 volumes of Tyrode's solution, and the quantity of the blood employed for one assay was 0.5 c.c.

The numeral of specimens and the quantity of adrenaline solution which is showed in c.c. and in concentration were added to each observation. For example, "0.1 1/2000" shows " 0.1 c.c. of adrenaline solution with the concentration of $1 / 2000 \mathrm{mgrm}$. in 1 c.c." i. e. $0.00005 \mathrm{mgrm}$. adrenaline. To show the I specimen, we used the numeral "I"

In all tracings, time intervals are 30 seconds.

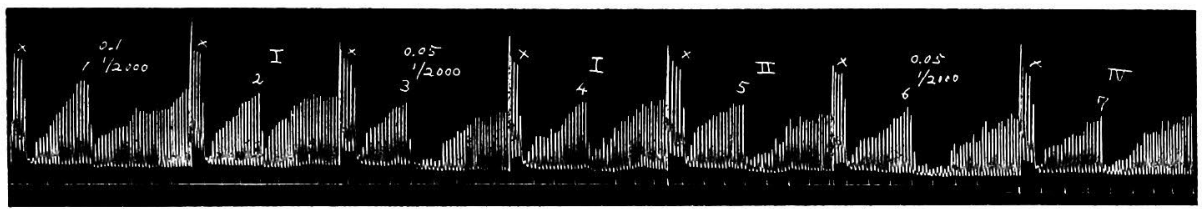

Fig. a. I: Weaker than $0.00005 \mathrm{mg}$. and a little weaker than $0.000025 \mathrm{mg}$. II: As strong as $0.000025 \mathrm{mg}$. and a little stronger than I. IV: About the same with 0.000 $025 \mathrm{mg}$. and weaker than $0.00005 \mathrm{mg}$.

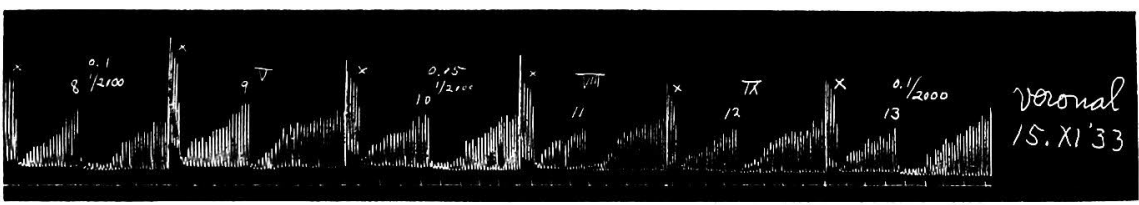

Fig. b. V: Weaker than $0.00005 \mathrm{mg}$. and a little weaker than or almost as strong as $0.000025 \mathrm{mg}$. VIII: As strong as $0.000025 \mathrm{mg}$. IX: As strong as VIII (0.000025 mg.) and a little weaker than $0.00005 \mathrm{mg}$.

To sum up:-

I: Weaker than $0.00005 \mathrm{mg}$. and a little weaker than $0.000025 \mathrm{mg}$. It was assayed at $0.00005-\mathrm{mg}$. per 1 c.c. II: As strong as $0.000025 \mathrm{mg}$. and a little stronger than I. It was taken as $0.00005 \mathrm{mg}$. per 1 c.c. IV : About the same with $0.000025 \mathrm{mg}$. and weaker than $0.00005 \mathrm{mg}$. It was taken as $0.00005 \mathrm{mg}$. in 1 c.c. V: Weaker than $0.00005 \mathrm{mg}$. and a little weaker than or almost as strong as $0.000025 \mathrm{mg}$. It was assayed at 0.00005 mg. per 1 c.c. VIII: As strong as $0.000025 \mathrm{mg}$. That is $0.00005 \mathrm{mg}$.per 1 c.c. IX: As strong as VIII (0.000025 mg.) and a little weaker than $0.00005 \mathrm{mg}$. It was taken as $0.00005 \mathrm{mg}$. in 1 c.c.

time needed to arrive at the minimum rate after the veronal application. Thereafter the rate tended again to recover.

The concentration of the suprarenal blood remained during veronal narcosis nearly unaltered; in Exps. 1 and 2 it increased but only 
very insignificantly, in Exp. 3 it remained entirely unaltered, and in Exp. 4 it underwent small variations, sometimes a small reduction, sometimes a small augmentation.

Consequently the epinephrine output per minute was measured reduced by the veronal anaesthesia though in a small degree.

$0.00001 \mathrm{mgrm}$. per kilo per minute before veronal and $0.000007-$ $0.000011 \mathrm{mgrm}$. after it in Exp. 1; $0.000012 \mathrm{mgrm}$. before and 0.000009-0.000018 mgrm. after in Exp. $2 ; 0.000025 \mathrm{mgrm}$. before and 0.000012-0.000022 mgrm. after in Exp. 3, and $0.00005 \mathrm{mgrm}$. before and 0.000003-0.000026 mgrm. after in Exp. 4.

The epinephrine secretion was found insignificantly reduced during the veronal anaesthesia. The poisoning symptoms in these dogs were of various degree according to the dose given, but no relation can be detected between the degree of poisoning and the rate of epinephrine secretion, because there was not detectable any definite difference rê the latter in these four experiments.

The blood sugar concentration was not altered by the veronal administration in a dose varying from $0.16-0.47$ grm. per kilo of body weight.

In Exp. 1, it was measured as $0.128 \% 10$ minutes before veronal, and on receiving the veronal it fluctuated between $0.114-0.135 \%$ in a lapse of 3 hours; in Exp. 2 a small reduction such as from $0.102 \%$ to $0.086 \%$ and $0.091 \%$ occurred within half an hour after veronal injection, but one hour later a complete recovery was estimated in the sugar concentration. In Exp. 3 no variation was witnessed in the blood sugar content throughout the whole experimental course. About the same was noted in Exp. 4. Some variations, strictly speaking, were measured in the blood sugar concentration during the veronal anaesthesia, but they were of an insignificant degree and of various signs.

During the veronal anaesthesia a body temperature fall was brought about and its magnitude depended upon the amount given. When 0.16 grm. per kilo (Exp. 1) and 0.25 grm. (Exp. 4) were given, the fall occurred only temporarily such as 1 hour or 1.5 hours, and its degree was never large, while 0.3 grm. veronal per kilo produced a large and long lasting decrease, and 0.47 grm. per kilo was capable of lowering the body temperature to $34^{\circ}$ within two hours and half an hour later the animal eventually died. In spite of detrimental conditions of the animal, such as a profound body temperature fall, relaxed muscles, weakened reflexes, disturbed circulation (blood very 
dark), etc., the blood sugar concentration was not altered at all and the epinephrine output rate was never measurable as increasing. Only a little decrease was noted in the latter. Before veronal the rate of secretion was $0.000025 \mathrm{mgrm}$. per kilo per minute and the minimum during the anaesthesia $0.000012 \mathrm{mgrm}$. These figures are very much like those obtained in this Laboratory when a dog was sleeping, $0.00001-0.000012 \mathrm{mgrm}$. during sleep against $0.000018-0.00003 \mathrm{mgrm}$. during quiet but not a sleeping period.

The heart rate decreased for a while when small doses were given (Exps. $1 \& 4$ ), but later it increased and finally far exceeded the initial rate, seemingly followed by an increasing of the body temperature. No large increase of the heart rate was noted in Exps. 2 and 4, in which the drug was given in somewhat large doses and the body temperature continued to fall. The respiration rate inclined to increase in Exps. 1 and 4, while it remained nearly unaltered in Exp. 2 and distinctly decreased in Exp. 3 ; such variations of the respiratory frequency correspond well to the general condition of animals and to the bearing of the body temperature.

\section{SUMMARY.}

Veronal was injected intravenously into dogs, non-anaesthetized in doses varying from 0.16 to $0.47 \mathrm{grms}$. per kilo of body weight. The suprarenal vein blood collected without and with narcosis, fasteningor laparotomy was tested for epinephrine by means of the rabbit intestine segment method.

The rate of epinephrine secretion from the suprarenal gland showed a tendency to reduce on poisoning, but only very slightly. And the blood sugar concentration remained practically unaltered.

2) Satake, Watanabé and Sugawara, Tohoku J. of Exp. Med., 1927, 9, 7. 